Portland State University

PDXScholar

\title{
Guarding Against Strain: The Moderating Role of Nonwork Experiences in the Relationship Between Work-Related Hypervigilance and Strain in Correctional Officers
}

Samantha Getzen

Portland State University

Follow this and additional works at: https://pdxscholar.library.pdx.edu/open_access_etds

Part of the Psychology Commons

Let us know how access to this document benefits you.

\section{Recommended Citation}

Getzen, Samantha, "Guarding Against Strain: The Moderating Role of Nonwork Experiences in the Relationship Between Work-Related Hypervigilance and Strain in Correctional Officers" (2021). Dissertations and Theses. Paper 5807.

https://doi.org/10.15760/etd.7678

This Thesis is brought to you for free and open access. It has been accepted for inclusion in Dissertations and Theses by an authorized administrator of PDXScholar. Please contact us if we can make this document more accessible: pdxscholar@pdx.edu. 
Guarding Against Strain:

The Moderating Role of Nonwork Experiences in the Relationship Between Work-Related Hypervigilance and Strain in Correctional Officers

by

Samantha Getzen

A thesis submitted in partial fulfillment of the requirements for the degree of

\author{
Master of Science \\ in \\ Psychology
}

\author{
Thesis Committee: \\ Charlotte Fritz, Chair \\ Leslie Hammer \\ Larry Martinez
}

Portland State University

2021 


\begin{abstract}
Correctional officers (COs) are expected to remain alert in order to maintain safety within the potentially hostile prison environment. As a result, COs experience high levels of work-related hypervigilance (WHV), which has been associated with negative health and wellbeing outcomes for COs. This study examines nonwork experiences as potential boundary conditions for the relationship between WHV and strain outcomes. It was hypothesized that nonwork experiences (psychological detachment, relaxation, mastery experiences, and exercise) would weaken the relationship between WHV and strain outcomes (emotional exhaustion, physical symptoms and impaired sleep). Data were analyzed from 166 COs in Oregon. A series of hierarchical moderated regressions were conducted to test the study hypotheses. Results supported two of the hypotheses, indicating that mastery experiences and exercise individually moderated the positive relationship between WHV and emotional exhaustion. Implications of these findings, limitations and future directions are discussed.
\end{abstract}




\section{Table of Contents}

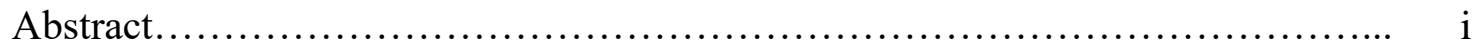

List of Tables..............................................................

List of Figures...................................................... iv

Introduction............................................................. 1

Theoretical Framework.................................................... 7

Hypothesis Development............................................ 10

Psychological Detachment as a Moderator.............................. 10

Relaxation as a Moderator......................................... 12

Mastery Experiences as a Moderator............................... 14

Exercise as a Moderator.......................................... 17

Method....................................................................... 20

Sample and Procedure......................................... 20

Measures................................................... 20

Results............................................................. 24

Preliminary Analyses........................................ 24

Hypothesis Testing ........................................... 25

Post-hoc Analyses ............................................ 28

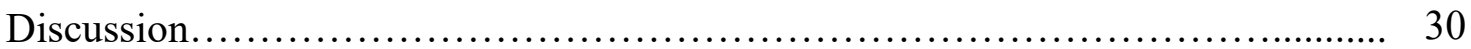

Theoretical Implications...................................... 30

Limitations and Future Directions................................. 34

Practical Implications............................................. 37

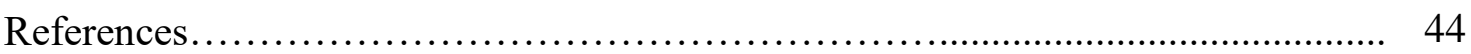

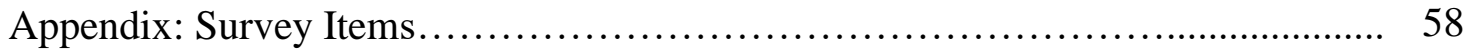




\section{List of Tables}

Table 1: Descriptive Statistics, Zero-Order Correlations, and Chronbach's Alpha

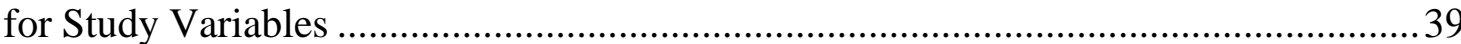

Table 2: Moderating Effects of Nonwork Experiences on Strain

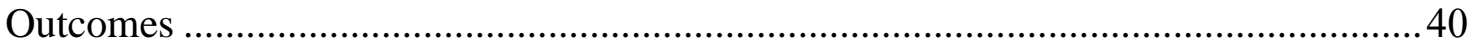

Table 3: Direct Effects of WHV and Nonwork Experiences on Strain Outcomes.... 41 


\section{List of Figures}

Figure 1: Conceptual Model

Figure 2: The moderating effect of mastery experiences on the relationship

between WHV and emotional exhaustion......

Figure 3: The moderating effect of exercise on the relationship between WHV and

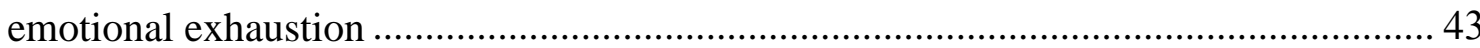




\section{Introduction}

Correctional Officers (COs) serve the critical role of maintaining a peaceful environment within prison facilities. In recent years, COs have faced heightened job demands due to a rapidly escalating population, staffing shortages, and high rates of turnover (Reid et al., 2017). The workload is such that a single officer may be responsible for monitoring 200 or more inmates at a given time (Neff \& Santo, 2020). Further, prison populations include increasing numbers of violent and mentally ill offenders (Konda et al., 2012). These conditions have been associated with a rise in violence against COs and inmates alike (Neff \& Santo, 2020). According to the Census of Adult State and Federal Correctional Facilities, in 2018, inmates in federal prisons committed prohibited acts (e.g., interpersonal violence, drug use, sexual abuse) at a rate of .92 acts per inmate, $24 \%$ of which were of the greatest severity (e.g., murder, taking hostages, sexual assault; United States Bureau of Justice Statistics, 2020). COs must be ready to respond to being physically assaulted by inmates, physically restraining inmates, or observing other violent acts at any time (Schaufeli \& Peeters, 2000).

Absenteeism due to nonfatal workplace injuries, and exposure to workplace violence are common among COs (Konda et al., 2012; U.S. Department of Labor, 2016). For example, in the past decade, COs in the U.S. experienced serious work-related injuries at a rate four times the average worker, half of which were the result of assault or other violent acts (Regehr et al., 2019). Therefore, in order to prevent death or serious injury to themselves, inmates, or coworkers, COs must remain alert at all times. This is 
GUARDING AGAINST STRAIN

referred to as work-related hypervigilance (WHV), defined as a continuous alertness due to a perceived threat in the working environment.

WHV is physically and psychologically taxing for COs, and is associated with strain outcomes such as exhaustion, impaired sleep, and physical symptoms of strain (e.g., digestive issues, nausea, headaches; Fritz et al., 2018). Additionally, research suggests that COs experience high levels of job demands such as lack of autonomy, high workload, mandatory overtime, role conflict, poor communication with supervisors, and low perceptions of organizational justice (Lambert et al., 2007; Schaufeli \& Peeters, 2000). The demands of this work have been associated with negative attitudes (e.g., low job satisfaction, turnover intentions; Konda et al., 2012), absenteeism, turnover, and importantly, highly unfavorable long-term health and wellbeing outcomes. These reactions have been referred to as "corrections fatigue," comprised of a myriad of symptoms such as negative personality changes, decreased health and functioning, and dysfunctional thinking (Denhof et al., 2014). Subsequently, COs are at a higher risk for suicide (Stack \& Tsoudis, 1997), and have an average life expectancy 12 to 15 years shorter than that of the general population (Parker, 2011).

Research has pointed to the importance of certain nonwork experiences for alleviating the association between job demands and poorer employee health and wellbeing (Kinnunen et al., 2010; Siltaloppi et al., 2009; Sonnentag \& Binneweis, 2013). For many, nonwork time represents an opportunity to recover from the cognitive and physical effort expended throughout the workday. Previous research has demonstrated that some nonwork experiences reduce or eliminate strain associated with stressful job 
demands (Sonnentag et al., 2017). These experiences are thought to reverse strain through positive experiences such as distraction, cessation of stressors on the body and mind, and through an induction of positive affect (Demerouti et al., 2009).

Given the prevalence of WHV for COs, this raises the following question: which nonwork experiences alleviate the relationship between WHV and strain? Past findings indicate that nonwork experiences can moderate the positive relationship between job demands and strain (Kinnunen et al., 2010; Sonnentag \& Fritz, 2015). However, the moderating effect of nonwork experiences has not been explored within high-risk occupations such as COs despite the pervasive strain reported by COs. Therefore, the aim of this research is to explore several different nonwork experiences as potential moderators in the relationship between CO WHV and strain. Specifically, this study will examine the several nonwork experiences, namely, psychological detachment, relaxation, mastery experiences, and exercise as moderators of the relationship between WHV and CO strain.

The current research contributes to the literature in several ways. First, it is of the utmost importance to understand the antecedents, outcomes, and boundary conditions through which employees in high safety-related occupations are able to recover from work stress. Emerging research has begun to examine WHV as a harmful job demand that COs frequently experience (Fritz et al., 2018). Previous research has shown that certain nonwork experiences can weaken the relationship between job demands and strain. However, it is not yet clear whether these nonwork experiences weaken the relationship between WHV and negative outcomes (e.g., impaired sleep, exhaustion and 
physical symptoms; Fritz et al., 2018) for COs. This research is critical due to the detrimental personal outcomes (e.g., impaired health and wellbeing). Further, high levels of strain have been shown to impair threat detection and cognitive functioning in COs (Basner et al. 2008; Lim \& Dinges 2010). Therefore, COs experiencing strain may be less able to maintain the safety of the inmates and fellow officers. In safety-related occupations such as corrections, policing, or healthcare, impaired cognition or suboptimal performance may pose a high risk to employees and others in serious danger (e.g., use of excessive force; Neely, 2012). Therefore, the physical and psychological restoration of COs during nonwork time may promote safety within prisons. The current research seeks to inform recommendations for how COs and others in similar professions might spend their nonwork time. By demonstrating which non-work experiences are associated with weaker relationships between WHV and strain outcomes, the findings of the current research may be used to inform future interventions in safety-related occupations.

Second, this research answers a call for a closer examination of the non-work experiences of blue-collar employees (Sonnentag et al., 2017). Much of the current research on nonwork experiences utilizes samples of knowledge workers, who are not exposed to environmental threats, and are unlikely to experience WHV. COs experience unique job demands (e.g., WHV) that have been associated with generally negative consequences (e.g., exhaustion, work-to-family conflict, negative affect, impaired sleep; Fritz et al., 2018). Therefore, more research is needed to understand the boundary conditions of these relationships for COs. This research will examine nonwork 
experiences as potential moderators of the relationship between stressors and strain for an under-researched demographic.

Third, the current research answers a call to examine job demands and the recovery process in conjunction (Bennet et al., 2018). This research focuses on WHV as a specific job demand, and several non-work experiences (e.g., psychological detachment, relaxation, mastery experiences, and exercise) as potential moderators. As WHV is a unique job demand, it is important to understand how the different nonwork experiences interact within this relationship in order to make practical recommendations for how COs can make the most of their nonwork time in order to alleviate work-related strain.

Finally, while an abundance of previous research has examined the moderating role of psychological detachment, relaxation, and exercise on the relationship between job demands and strain outcomes (e.g. Sonnentag \& Fritz, 2015; Sonnentag \& Fritz, 2007; Sonnentag \& Jeldon, 2009), less is known about the role of mastery experiences in this relationship. This study includes mastery experiences as a potential resource-building activity that COs may engage in during nonwork time, alongside the other wellestablished nonwork experiences that are associated with recovery from job demands. It is important to understand whether mastery experiences can weaken the relationship between job demands and strain, as individuals have different preferences as to how they spend their nonwork time. Whereas some individuals may prefer nonwork activities that require little or no effort, others may benefit from being challenged (e.g. mastery experiences). This research may inform whether mastery experiences are worth the 
GUARDING AGAINST STRAIN

investment of effort, or if individuals would benefit from conserving, rather than investing their resources. 


\section{Theoretical Framework}

I will draw Cognitive Activation Theory of Stress (CATS; Ursin \& Eriksen, 2004), Conservation of Resources theory (COR; Hobfoll, 2018), and the Effort-Recovery Model (ERM; Meijman \& Mulder, 1998), to guide my rationale for this research. According to CATS, when individuals anticipate a threat within the environment, physiological arousal increases (e.g. increased heart rate, wakefulness, increased levels of cortisol; Ursin \& Eriksen, 2004). CATS theory refers to this increase in arousal as “activation" (Ursin \& Eriksen, 2004). The activation serves as an alarm that compels the individual to address the threatening stimulus and is considered an adaptive mechanism (Meurs \& Perrewé, 2011). When the threatening stimulus passes, the alarm ceases, and physiological systems (i.e.., activation) return to baseline. However, when individuals must be continuously prepared for a threat within the environment (i.e., WHV), activation is sustained (Fritz et al., 2018; Ursin \& Eriksen, 2004). Activation may continue into nonwork time when individuals continue to think about the threatening stimulus, referred to as preservative cognition (Brosschot et al., 2005). Similarly, the anticipation of future threats and recollection of past threats prevents the individual from returning to baseline levels of activation. Continuous or repeated activation results in strain manifested in disease, (Brosschot et al., 2005), impaired cognitive and physical functioning (Seeman et al., 1997), and increased burnout symptoms (Juster et al., 2011). From this perspective, WHV is a form of activation (Ursin \& Eriksen, 2004), that persists into during nonwork time in order to detect and react to possible threats in the environment. (Kimble et al., 2013). 
GUARDING AGAINST STRAIN

Conservation of resources theory (COR; Hobfoll, 2018) argues that individuals

strive to protect and gain resources. This includes resources such as energy resources (e.g. vigor; Bennet et al., 2018), that are often expended while facing stressful job demands (e.g. WHV). However, according to the Resource Investment principle, individuals may take action to protect themselves against strain by engaging in activities that reduce resource depletion or facilitate resource replenishment. While these activities require an initial investment of resources (e.g., time, attention), the resources gained as a result of engaging in a specific experience outweigh the initial resource investment. However, if individuals continue to lose resources and are not able to replenish lost resources, they will experience a state of resource-depletion which is associated with strain. For example, COs may need to invest resources such as time or attention into experiences that generate personal resources such as energy or increased positive mood (Hobfoll, 2018). COR Theory further argues that being in a state of resource-depletion puts individuals at risk for further resource loss in a process known as a "loss spiral" (Hobfoll, 2018). Therefore, resource replenishment is especially valuable to individuals experiencing resource loss (e.g., increased work-related strain). Within this framework, WHV is considered a resource-draining job demand, putting COs at risk for resource depletion and loss-spirals (Fritz et al., 2018). However, nonwork experiences that facilitate resource replenishment or resource gain should impede further resource loss thereby weakening the relationship between WHV and its association with strain outcomes. 
GUARDING AGAINST STRAIN

The Effort-Recovery Model (ERM; Meijman \& Mulder, 1998) argues that job demands and stressful experiences in the workplace contributes to what is referred to as "load reactions," (e.g., increased distress). Once the stressful job demands are removed, the employee is able to return to the pre-stressor state, wherein cognitive, emotional and physical systems are normalized. However, when the load reactions (e.g., distress) persist through non-work hours, one's ability to recover from work stress is hindered leaving individuals in sub-optimal condition at the start of the next workday (Geurts \& Sonnentag, 2006). In order to compensate, individuals must invest additional effort in order to perform adequately (Demerouti et al., 2009). This creates a cycle wherein the additional effort increases the intensity of load reactions and therefore a higher demand on the recovery process in order to return to the pre-stressor state. If recovery from work stress remains incomplete, acute load reactions accumulate into chronic load reactions known as allostatic load (McEwen, 1998; Ursen \& Eriksen, 2004). Allostatic load, or "allostasis" is associated with physical and cognitive strain outcomes such as chronically elevated heart rate, hypertension, chronic fatigue, and persistent sleep problems (Demerouti et al., 2009). In order to avoid accumulating allostatic load and the associated health consequences, COs must return to the pre-stressor state during nonwork time, allowing the body and mind to recover from work stress. 


\section{Hypothesis Development}

Research by Fritz and colleagues (2018) found that WHV is related to strain evidenced by exhaustion, physical symptoms, and impaired sleep quality and quantity in COs. Exhaustion is a commonly studied strain reaction that involves feeling emotionally drained and worn out after work (Demerouti et al. 2003). Physical symptoms refer to the health indicators that become apparent over time as a result of strain (e.g. headaches, fatigue, and digestive problems; Spector \& Jex, 1998). Impaired sleep entails both poor sleep quality and quantity, which are detrimental to restorative processes (Barnes et al. 2012). Research on recovery from work demands suggests that nonwork experiences can alleviate the relationship between job demands and strain (Sonnentag et al., 2017). I argue that certain nonwork experiences may provide a chance for COs to recover from work stress, thereby weakening the relationships between WHV and strain outcomes. According to previous research, each nonwork experience is associated with different cognitive and physical states, and therefore should be examined separately (Bennet et al., 2018). Whereas some nonwork experiences aid in recovery by ending the psychological and physical activation created by work demands (Sonnentag \& Fritz, 2007, Ursin \& Eriksen, 2004), other nonwork experiences build and replenish resources depleted by stressful work (Hobfoll, 2018). I will draw upon the proposed theories to examine how certain non-work experiences may moderate the relationship between WHV and strain by reducing the cognitive activation, decreasing load reactions, restoring depleted resources, and generating positive resource gain.

\section{Psychological Detachment as a Moderator}


Psychological detachment refers to an individual's sense of being away from work during nonwork time (Sonnentag \& Fritz, 2007). Specifically, psychological detachment entails the cognitive disengagement from work, and an absence of worry, rumination, or repetitive thoughts during nonwork time (Sonnentag \& Fritz, 2015). I propose that psychological detachment will weaken the positive relationship between WHV and strain in COs. The Effort Recovery Model (Meijman \& Mulder, 1998) proposes that individuals' cognitive and physiological systems are able to recover when they are no longer in use (e.g. nonwork time). Psychological detachment allows these systems to return to the pre-stressor state, and prevent further resource loss, thereby alleviating the relationship between job demands and strain. For example, when COs disengage from thoughts about the danger they might have faced at work that day (high detachment), the threatening environment is less mentally present. However, if COs continue to engage in work-related tasks or thoughts (low detachment), COs will remain in a state of resource-depletion, and therefore sustain load reactions. In line with the ERM (Meijman \& Mulder, 1998), persisting load reactions should manifest in impaired sleep, exhaustion, and physical symptoms of strain (Fritz et al., 2018).

Previous research has examined psychological detachment as a moderator within the stressor-strain relationship. For example, Moreno-Jiménez and colleagues (2009) found that psychological detachment moderated the relationship between workplace bullying and psychological strain. Specifically, the relationship between workplace bullying and strain was weaker for employees who reported higher levels of psychological detachment. Similarly, in a day-level study, Sonnentag and Binneweis 
GUARDING AGAINST STRAIN

(2013) found that psychological detachment moderated the relationship between affective distress at work and affective distress at home such that individuals who experienced psychological detachment in the evening experienced less affective distress the following morning. Therefore, I hypothesize that the positive relationship between WHV and strain outcomes should be weaker for individuals who experience higher psychological detachment during nonwork time.

Hypotheses 1a-d: (a) Psychological detachment will moderate the positive relationship between WHV and exhaustion such that the relationship is weaker for COs higher in psychological detachment.

(b) Psychological detachment will moderate the positive relationships between WHV and physical symptoms such that the relationship is weaker for COs higher in psychological detachment.

(c) Psychological detachment will moderate the negative relationships between WHV and sleep quality and quantity such that the relationship is weaker for COs higher in psychological detachment.

(d) Psychological detachment will moderate the negative relationships between WHV and sleep quantity such that the relationship is weaker for COs higher in psychological detachment.

\section{Relaxation as a Moderator}

Relaxation is a state characterized by low physical and mental activation as well as high positive affect (Sonnentag \& Fritz, 2007). During nonwork time, relaxation entails low-effort activities such as taking a leisurely walk or listening to relaxing music. 
I propose that relaxation during nonwork time will moderate the positive relationship between WHV and CO strain (e.g., emotional exhaustion, physical symptoms of strain, and impaired sleep) by reducing load reactions, as well as replenishing depleted resources. The ERM (Meijman \& Mulder, 1998) argues that job demands contribute to load reactions, such as distress. When these job demands are removed, individuals are able to reduce load reactions and return to the pre-stressor state. For COs, WHV contributes to load reactions, which over time can result in strain manifested in emotional exhaustion, impaired sleep, and physical symptoms. COs who experience relaxation during nonwork time should reduce load reactions, allowing for the recuperation of the cognitive and physical systems exhausted by WHV.

Further, in line with COR theory (Hobfoll, 2018), job demands are associated with resource depletion. When individuals' resources are depleted continuously without being replenished, individuals are at risk for experiencing a resource loss spiral. Relaxation is restful and pleasurable in nature and has been associated with an increase of positive resources such as positive mood, vigor, and positive wellbeing (Bennet et al., 2018; Fredrickson, 2001). For COs, WHV can be considered a resource-depleting job demand, leaving them susceptible to strain outcomes such as exhaustion, impaired sleep and physical symptoms if these resources are not replenished during nonwork time. However, officers who experience relaxation during nonwork time should replenish depleted resources, as well as experience an increase of personal resources (e.g. positive mood, vitality, positive wellbeing). Therefore, the increase in resources weaken the relationship between job demands and strain. 
Relaxation has been examined as a moderator in the relationship between job demands and strain in previous research. For example, Shimazu and colleagues (2012) found that relaxation moderated the relationship between psychological distress and physical complaints such that employees who experienced higher levels of relaxation during nonwork time reported lower levels of psychological distress and physical complaints than employees who experienced lower levels of relaxation. Therefore, I propose that the positive relationship between WHV and strain outcomes should be weaker for individuals who experience high levels of relaxation during nonwork time.

Hypotheses 2a-c: (a) Relaxation will moderate the positive relationship between WHV and exhaustion such that the relationship is weaker for COs higher in relaxation.

(b) Relaxation will moderate the positive relationships between WHV and physical symptoms such that the relationship is weaker for COs higher in relaxation.

(c) Relaxation will moderate the negative relationships between WHV and sleep quality and quantity such that the relationship is weaker for COs higher in relaxation.

(d) Relaxation will moderate the negative relationships between WHV and sleep quantity such that the relationship is weaker for COs higher in relaxation.

\section{Mastery Experiences as a Moderator}

Mastery experiences during nonwork time refer to experiences that challenge individuals or allow them to broaden their horizons by learning something new (e.g. 
GUARDING AGAINST STRAIN

learning a new hobby or language) (Sonnentag \& Fritz, 2007). I propose that mastery experiences moderate the positive relationship between WHV and strain outcomes in COs. The role of mastery experiences in the relationship between job demands and strain is twofold. First, mastery experiences are associated with reduced work-related cognitive activation (Sonnentag, 2001). According to CATS (Ursin \& Eriksen, 2004), cognitive activation is sustained through preservative cognition. In the context of COs, this means that COs will remain mentally alert and in a state of arousal even during nonwork time as they continue to think about various negative events they experienced at work (i.e. violence at work), or through worrying about potential future threats at work. However, mastery experiences should weaken the positive relationship between WHV and strain. This is because COs who engage in mastery experiences will be cognitively engaged in an activity rather than in work-related preservative cognition during nonwork time. Whereas psychological detachment refers to the absence of work-related thoughts during non-work hours, mastery experiences require the individual to be actively engaged in learning opportunities that challenge and engage the individual's capabilities (Sonnentag \& Fritz, 2007).

Second, mastery experiences are associated with an increase in personal resources (i.e., skills and personal traits; Bennet et al., 2018, Hobfoll et al., 2018). According to COR Theory's Resource Investment Principle, people must invest resources to protect themselves against future resource loss, to recover from resource loss, and to gain new resources (Hobfoll et al., 2018). While mastery experiences require effort, they are a form of resource investment that can generate further resources, thereby weakening the 
GUARDING AGAINST STRAIN

relationship between WHV and strain. Specifically, mastery experiences may foster personal resources such as self-efficacy and perceived competence which may enhance an individual's belief that they can overcome various difficulties in their life (Bandura, 2001; Frayne \& Geringer, 2000; Hobfoll et al., 2018). These personal resources provide COs with reassurance in their ability to deal with threats of violence in the workplace, and therefore are able to thwart outcomes such as exhaustion, impaired sleep and physical symptoms. Previous research shows that mastery experiences can moderate the relationship between job demands and strain. For example, Siltaloppi and colleagues (2009) found that mastery experiences moderated the negative relationship between low levels of job control and need for recovery, a short-term indicator of strain, such that this relationship was weaker for those who engaged in high levels of mastery experiences during nonwork time. Therefore, I propose that the positive relationship between WHV and strain outcomes should be weaker for individuals higher in mastery experiences during nonwork time compared to those lower in mastery experiences.

Hypothesis 3a-c: (a) Mastery experiences will moderate the positive relationship between WHV and exhaustion such that the relationship is weaker for COs higher in mastery experiences.

(b) Mastery experiences will moderate the positive relationships between WHV and physical symptoms such that the relationship is weaker for COs higher in mastery experiences. 
(c) Mastery experiences will moderate the negative relationships between WHV and sleep quality and quantity such that the relationship is weaker for COs higher in mastery experiences.

experiences.

(d) Mastery experiences will moderate the negative relationships between WHV and sleep quantity such that the relationship is weaker for COs higher in mastery experiences.

\section{Exercise as a Moderator}

Exercise refers to the physical activities that engage individuals cardiovascular and musculoskeletal systems for health-promotion or leisure (e.g. running, lifting weights, cycling; Sonnentag, 2001). I propose that exercise should moderate the positive relationship between WHV and strain in COs through an induction of a positive state, as well as distraction from work-related thoughts (e.g. preservative cognition). First, research has found that exercise is related to elevated levels of endorphins (Grossman et al., 1984; Raglin \& Morgan, 1985) and hormones (e.g. noradrenaline, serotonin, and dopamine) that create an anti-depressant-like effect (Cox, 2002). According to CATS, a perceived threat is associated with negative cognitive, and physical activation that may continue into nonwork time, further taxing cognitive and physical systems (Meurs \& Perrewé, 2011) becoming apparent in strain outcomes such as exhaustion, impaired sleep and physical symptoms. However, exercise should weaken the relationship between WHV and strain. Exercise reduces cognitive and physical activation by promoting a state of relaxation and positive mood (Bakker et al., 2013), and reduced 
fatigue (Rook \& Zijlstra, 2006). This relaxed state and positive mood during nonwork time should weaken then relationship between WHV and exhaustion, impaired sleep and physical symptoms by reducing cognitive and physical activation.

Second, studies have shown that physical activity can draw individuals' attention away from job demands (Sonnentag, 2001; Toker \& Biron, 2012). CATS argues that activation can be sustained during nonwork time through preservative cognition (i.e., worry, rumination; Meurs \& Perrewé, 2011, Ursin \& Eriksen, 2004). This means that for COs, worrying about future threats, as well as ruminating on past threats can prevent COs from decreasing levels of cognitive and physical activation during nonwork time (Fritz et al., 2018). Exercise requires attention and effort, meaning that COs will have a lower capacity to dwell on past or future threats (Toker \& Biron, 2012). COs who engage in exercise during nonwork time should experience fewer repetitive thoughts about past and future threats in the workplace, and therefore lower levels of cognitive and physical arousal. In line with CATS, lower level of arousal during nonwork time should weaken the relationship between WHV and exhaustion, impaired sleep and physical symptoms.

Physical activity has been examined as a moderator within the job demands-strain relationship for various stressors as well as outcomes. For example, Barber and colleagues (2017) investigated the spillover relationship between undermining (i.e., the display of negative emotions and behaviors; Hoobler \& Brass, 2006) experienced at work and undermining displayed at home through poor sleep quality. They found that exercise moderated the indirect relationship between work undermining and home 
GUARDING AGAINST STRAIN

undermining such that this relationship was weaker when individuals reported lower, but not higher levels of exercise. Additionally, a qualitative study conducted with firefighters found that physical activity weakened the positive relationship between job demands (e.g. sub-standard equipment, conveying news of tragedy) and symptoms of mental health impairment (e.g. depression, anger, anxiety) such that the relationship was weaker when individuals exercised more (Sawhney et al., 2018). Therefore, I predict that the positive relationship between WHV and strain outcomes should be weaker for individuals who engage in higher versus lower levels of exercise during nonwork time.

Hypothesis 4a-c: (a) Exercise will moderate the positive relationship between WHV and exhaustion such that the relationship is weaker for COs higher in exercise.

(b) Exercise will moderate the positive relationships between WHV and physical symptoms such that the relationship is weaker for COs higher in exercise.

(c) Exercise will moderate the negative relationships between WHV and sleep quality and quantity such that the relationship is weaker for COs higher in exercise.

(d) Exercise will moderate the negative relationships between WHV and sleep quantity such that the relationship is weaker for COs higher in exercise. 


\section{Method}

\section{Sample and Procedure}

For this project, I was given access to archival data collected in 2014 as part of a larger data collection for a project with the Oregon Department of Corrections (ODOC). The organizations included in this study were two medium-security prisons located in Northeastern Oregon. Prior to survey distribution, the researchers toured the two facilities in which the study was conducted. They explained the purpose of the study and conducted interviews with supervisory staff to discuss logistics of the study as well as any concerns. After gaining ODOC approval, the researchers then created the survey materials. Survey materials were sent by mail to the corrections facilities and distributed to participants over the course of three weeks. Each survey package contained a stamped envelope addressed to the PI of the initial study. Surveys were distributed to a total of 596 COs. Surveys were returned by 166 COs $(N=166)$, resulting in a response rate of 28\%. Participants were emailed a \$10 Amazon gift card. The sample consisted of predominantly male $(81 \%)$ and Caucasian $(85 \%)$ participants. Participants reported an average of 43.18 hours worked per week $(S D=7.90)$, and an average tenure of 12.04 years $(S D=8.22)$.

\section{Measures}

COs were asked to respond to the following measures in reference to the past month. Full survey materials are located in the Appendix.

WHV was assessed using eight items from Fritz et al.’s (2018) Hypervigilance scale. Participants were asked to indicate the extent to which they agreed with each item 
on a Likert scale ranging from 1 (not at all) to 5 (very much). Sample items from this scale include, "Bad things may have happened if I had not constantly been looking out for danger," and "I maintained awareness of the actions of others that may have caused me harm." Cronbach's alpha for this scale was .89 .

Psychological Detachment was measured using four items from the Recovery Experience Questionnaire (REQ; Sonnentag \& Fritz, 2007). Participants were asked to indicate the extent to which they agreed with each item based on their non-work time on a Likert scale ranging from 1 (not at all) to 5 (very much). Sample items from this scale include, "I didn't think about work at all," and "I got a break from the demands of work." Cronbach's alpha for this scale was .87.

Relaxation was measured using four items from the Recovery Experience Questionnaire (REQ; Sonnentag \& Fritz, 2007). Participants were asked to indicate the extent to which they agreed with each item based on their non-work time on a Likert scale ranging from 1 (not at all) to 5 (very much). Sample items from this scale include, "I kicked back and relaxed," and "I did things that were relaxing." Cronbach's alpha for this scale was .94 .

Mastery Experiences were measured using four items from the Recovery Experience Questionnaire (REQ; Sonnentag \& Fritz, 2007). Participants were asked to indicate the extent to which they agreed with each item based on their non-work time using a Likert scale ranging from 1 (not at all) to 5 (very much). Sample items from this scale include, "I learned new things," and "I did things that challenged me." Cronbach's alpha for this scale was .91. 
Exercise was assessed using six items from Elliot and colleagues' (2007) physical activity questionnaire. Participants were asked to indicate the frequency with which they engaged in physical activity. Sample items from this scale include, "In a typical week, how many days do you take part in any physical activity long enough to work up a sweat?" and "How many days per week did you exercise to strengthen or tone your muscles, such as push-ups, sit-ups, or weightlifting?”

Exhaustion was assessed using eight items from the Oldenburg Burnout Inventory (OLBI; Demerouti et al., 2008). Participants were asked to indicate the extent to which they agreed with each item on a Likert scale ranging from 1 (not at all) to 5 (very much). Sample items from this scale included, "There were days that I felt already tired before I went to work," and "After my work, I usually felt worn out and weary." Cronbach's alpha for this scale was .85 .

Sleep Quality and Quantity were assessed using two items from the Pittsburg Sleep Quality Index (Buysse et al., 1989). This scale asked participants to indicate their average hours of sleep per night over the past month, as well as sleep quality on a Likert scale ranging from 1 (very bad) to 5 (very good).

Physical Symptoms were assessed using 12 items from the Physical Symptoms Inventory (Spector \& Jex, 1997). Participants were asked to indicate the frequency with which they experienced a symptom over the past month on a Likert scale ranging from 1 (not at all) to 5 (everyday). Symptoms from this scale included an upset stomach or nausea, dizziness, and tiredness or fatigue. 
Control Variables. Based on previous research, several control variables that are theoretically linked to WHV and strain were included in this data collection. These variables included hours worked per week on average over the past month, veteran status, security level, job tenure, and whether one experienced a recent physical confrontation with an inmate. For example, veteran status may be related to a higher frequency of past traumatic experiences, and therefore linked to higher WHV (Kimble et al., 2013). Similarly, measures of security level of the prison (e.g. minimum, medium or maximum), as well as whether the $\mathrm{CO}$ has had any recent physical altercation with an inmate were obtained, as both may relate to higher levels of WHV. Further, organizational tenure may be associated with organizational privileges (e.g., favorable shifts), and therefore lower strain. Conversely, organizational tenure may be associated with more accumulated strain over years. 


\section{Results}

\section{Preliminary Analyses}

The data relevant to the current study were cleaned and examined for missingness. Relevant items from the WHV scale and the exhaustion scale were reversecoded and then new scales were created in the data set. Next, scale reliabilities and scale means were calculated. I then examined descriptive statistics, histograms and Q-Q plots to assess normality of the data. Based on the histogram, the results indicated that WHV was negatively skewed $-1.37(S E=.19)$, indicating that COs in this sample reported on average higher levels of WHV. I then examined correlations between each construct and the potential control variables. Correlations that exceeded a threshold of $r=.15$ were considered high enough to warrant including them as control variables. There were significant correlations between veteran status and exhaustion $(r=.23, p<.01)$, as well as CO tenure and sleep quantity $(r=-.19 p<.05)$ and were therefore used as control variables in subsequent analyses. Recent physical confrontation with an inmate and security level were not significantly correlated with study outcomes and therefore were excluded from analyses. All means, standard deviations, and correlations can be found in Table 1.

Prior to testing my hypotheses, I examined the direct relationships between nonwork experiences (psychological detachment, relaxation, exercise, and mastery experiences) and strain outcomes (emotional exhaustion, physical symptoms, and impaired sleep quality and quantity). As expected, the majority of the direct relationships 
between nonwork experiences and strain outcomes were significant and negative (see

Table 3).

\section{Hypothesis Testing}

In order to determine whether the relationship between WHV and strain outcomes for COs was moderated by nonwork experiences (i.e.., psychological detachment, relaxation, mastery, exercise), I used Hayes (2017) PROCESS macro Model 1 for moderation. PROCESS uses bootstrapping to calculate direct and interaction effects for low ( $-1 \mathrm{SD})$, average, and high (+1 SD) levels of the moderators.

Unstandardized coefficients for each model tested are located in Table 2. Hypothesis 1a predicted that the relationship between WHV and exhaustion is moderated by psychological detachment. Results indicated that the interaction was non-significant $(\gamma$ $=-.07, S E=.07, n s)$. Therefore, Hypothesis 1a was not supported. Hypotheses $1 \mathrm{~b}$ predicted that the relationship between WHV and physical symptoms is moderated by psychological detachment. Results indicated that the interaction was non-significant $(\gamma=$ $08, S E=.06, n s)$. Therefore, Hypothesis $1 \mathrm{~b}$ was not supported. Hypotheses 1c predicted that the relationship between WHV and sleep quality is moderated by psychological detachment. Psychological detachment was not a significant moderator of the relationship between WHV and sleep quality $(\gamma=.07, S E=.11, n s)$. Therefore, Hypothesis 1c was not supported. Hypotheses 1d predicted that the relationship between WHV and sleep quantity is moderated by psychological detachment. Psychological detachment was not a significant moderator of the relationship between WHV sleep quantity $(\gamma=.13, S E=.13$, $n s)$. Therefore, Hypothesis 1d was not supported. 
Hypothesis $2 \mathrm{a}$ predicted that the relationship between WHV and exhaustion is moderated by relaxation. Results indicated that the interaction was non-significant $(\gamma=-$ $.13, S E=.08, n s)$. Therefore, Hypothesis $2 \mathrm{a}$ was not supported. Hypotheses $2 \mathrm{~b}$ predicted that the relationship between WHV and physical symptoms is moderated by relaxation. Results indicated that the interaction was non-significant $(\gamma=.07, S E=.07, n s)$. Therefore, Hypothesis $2 \mathrm{~b}$ was not supported. Hypotheses $2 \mathrm{c}$ predicted that the relationship between WHV and sleep quality is moderated by relaxation. Results indicated that relaxation was not a significant moderator of the relationship between WHV and sleep quality $(\gamma=.01, S E=.14, n s)$ Therefore, Hypothesis $2 \mathrm{c}$ was not supported. Hypotheses $2 \mathrm{~d}$ predicted that the relationship between WHV and sleep quantity is moderated by relaxation. Results indicated that relaxation was not a significant moderator of the relationship between WHV and quantity $(\gamma=-.01, S E=.05$, $n s)$. Therefore, Hypothesis $2 \mathrm{~d}$ was not supported.

Hypothesis 3a predicted that the relationship between WHV and exhaustion is moderated by mastery experiences. Results indicated that the interaction effect was significant $(\gamma=-.23, S E=.08, p<.001)$. Simple slopes were then graphically examined to determine the nature of the interaction (Aiken \& West, 1991). In support of Hypothesis 3a, I found that the relationship between WHV and emotional exhaustion was weaker for COs who reported higher levels of mastery experiences compared to COs who reported lower levels of mastery experiences (see Figure 1). Therefore, Hypothesis 3a was supported. Hypotheses $3 \mathrm{~b}$ predicted that the relationship between WHV and physical symptoms is moderated by mastery experiences. Results indicated that the interaction 
was non-significant $(\gamma=.02, S E=.67, n s)$. Therefore, Hypothesis $3 \mathrm{~b}$ was not supported.

Hypotheses $3 \mathrm{c}$ predicted that the relationship between WHV and sleep quantity is

moderated by mastery experiences. Results indicated that mastery experiences were not a significant moderator of the relationship between WHV and sleep quality $(\gamma=.04, S E=$ $.13, n s)$ ). Therefore, Hypothesis $3 \mathrm{c}$ was not supported. Hypotheses $3 \mathrm{~d}$ predicted that the relationship between WHV and sleep quantity is moderated by mastery experiences. Results indicated that mastery experiences were not a significant moderator of the relationship between WHV and sleep quantity $(\gamma=.07, S E=.11, n s)$. Therefore, Hypothesis 3d was not supported.

Hypothesis $4 \mathrm{a}$ predicted that the relationship between WHV and exhaustion is moderated by exercise. Results indicated that the interaction effect was significant $(\gamma=-$ $.04, S E=.01, p<.05)$. Simple slopes were then graphically examined to determine the nature of the interaction (Aiken \& West, 1991). In support of Hypothesis 4a, I found that the relationship between WHV and emotional exhaustion was weaker for COs who reported higher levels of exercise compared to COs who reported lower levels of exercise (see Figure 2). Therefore, Hypothesis 4a was supported. Hypotheses $4 \mathrm{~b}$ predicted that the relationship between WHV and physical symptoms is moderated by exercise. The interaction between WHV and exercise was non-significant $(\gamma=-.01, S E=.01, n s)$. Therefore, Hypothesis $4 \mathrm{~b}$ was not supported. Hypotheses $4 \mathrm{c}$ predicted that the relationship between WHV and sleep quality and quantity is moderated by exercise. The higher-order unconditional interaction between WHV and exercise was non-significant $(\gamma$ $=.03, S E=.02, p=.08)$ Therefore, Hypothesis $4 \mathrm{c}$ was not supported. Hypotheses $4 \mathrm{~d}$ 
predicted that the relationship between WHV and sleep quantity is moderated by exercise. The higher-order unconditional interaction between WHV and exercise was nonsignificant $(\gamma=.02, S E=.02, n s)$. Therefore, Hypothesis $4 \mathrm{~d}$ was not supported.

\section{Post-hoc Analyses}

When analyzing skewed or non-normally distributed data, it is common practice to conduct log transformations (Feng et al., 2019). Due to the non-normal distribution of the predictor variable (WHV), the data were transformed such that $[\mathrm{x}=\ln (\mathrm{x})]$. Overall, I found that this transformation did not improve the normality of the distribution. I then used Hayes' PROCESS macro (2017) to re-test my hypotheses with the transformed predictor variable. The transformation did not change the significance levels of any of the hypothesized relationships.

Two control variables, veteran status and organizational tenure, surpassed the correlation threshold $(r=.15)$ to warrant further examination. The initial hypothesis tests excluded these control variables. The 16 regression models were repeated with the inclusion of organizational tenure and veteran status as control variables. Both of the significant interaction effects remained significant after inclusion of these control variables. All of the non-significant interaction effects remained non-significant after the inclusion of the control variables as well.

As the current study tested 16 separate regression models, it was important to consider the possibility that any significant findings may be due to chance. In order to account for family-wise error inflation of Type 1 error, Bonferroni type adjustments were applied to the significance criterion. This correction adjusts the $p$-value needed to achieve 
significance by dividing the criterion (e.g., .05) by the number of outcome families

included in the analyses. The current study included only one outcome family with four components (exhaustion, physical symptoms, sleep quality, and sleep quantity).

Therefore, the outcomes were evaluated at a significance criterion of $p<.0125$. Overall, the correction for Type 1 error did not affect the results.

Research has suggested that there may be a reciprocal relationship between job demands and exhaustion, as employees' appraisals of their work environments change over time as health status changes. Specifically, DeLange and colleagues (2004) found that employees who experience emotional exhaustion appraise their work environments more negatively over time. Similarly, in a military sample of 1539 soldiers, Tucker and colleagues (2008) found that higher strain was associated with higher subsequent work overload and lower control over a six-month time period. These findings are in line with COR theory’s loss spiral corollary (Hobfoll et al., 2018). Therefore, I conducted regression analyses to determine whether strain predicted levels of WHV. The results indicated that exhaustion significantly predicted WHV $(B=.34, S E=.06, p<.001)$ in that COs higher in exhaustion reported higher levels of WHV. Physical symptoms, poor sleep quality, and poor sleep quantity, however, did not significantly predict WHV. 


\section{Discussion}

The work environment of a prison exposes COs to job demands unique to safetyrelated occupations, such as WHV. Therefore, in line with COR theory (Hobfoll, 2018), CATS (Ursin \& Eriksen, 2004), and the ERM (Meijman \& Mulder, 1998), the aim of the current study was to investigate whether nonwork experiences moderated the relationship between WHV and strain outcomes for COs. Specifically, I hypothesized that nonwork experiences (e.g. psychological detachment, relaxation, mastery experiences, and exercise) would weaken the positive relationship between WHV and strain outcomes. With two exceptions, results from this study failed to support nonwork experiences as moderators in the relationship between WHV and strain outcomes for COs. Specifically, mastery experiences and exercise individually moderated the relationship between WHV and exhaustion.

\section{Theoretical Implications}

The current study offers several theoretical implications for employees in safetyrelated occupations. First, my findings suggest that for COs, engaging in mastery experiences during nonwork time such as learning a new skill or hobby weakens the relationship between WHV and emotional exhaustion. Thus, in line with COR Theory's resource-investment principle, COs who engage in mastery experiences during nonwork time seem to build personal resources which alleviates the relationship between WHV and increased emotional exhaustion. For example, while engaging in mastery experiences requires an individual to invest time and energy resources, these experiences 
may generate personal resources (e.g., vitality, self-efficacy.) This influx of resources may alleviate the "worn out" feeling of emotional exhaustion resulting from WHV. Additionally, because they tend to require sustained attention, mastery experiences also serve as a distraction from work-related thoughts, thereby weakening the relationship between WHV and emotion exhaustion.Second, my findings indicated that exercise moderated the relationship between WHV and emotional exhaustion. This finding also supports COR Theory's resource- investment principle. Similar to mastery experiences, exercise is a nonwork experience that requires an initial investment of time and energy resources, and is associated with increased personal resources such as positive mood and an increased feeling of energy (Bultmann et al., 2002; Kristal-Boneh et al., 1996). These restored energy resources seem to alleviate the exhausted feeling associated with WHV. This is line with previous research that has demonstrated the moderating effect of exercise on the relationship with job-related strain and employee ill-being. For example, in a seven-year, three-wave longitudinal study, Biron and Toker (2012) found that initial levels of burnout predicted subsequent levels of depression. However, physical activity moderated the relationship between levels of burnout at Time 1 and subsequent levels of depression at Times 2 and 3, such that individuals who engaged in the higher levels of physical activity demonstrated the smallest increase in depression, whereas individuals who engaged in the lower levels of physical activity demonstrated the largest increases in depression.

Taken together, these results suggest that active, as opposed to passive nonwork experiences may be more effective for alleviating the relationship between WHV and 
GUARDING AGAINST STRAIN

emotional exhaustion. These experiences are thought to contribute to the work-life balance of employees, adding richness to life over and above that of rest afforded by downtime (Winwood et al., 2007). Indeed, previous research has found that participating in creative hobbies during nonwork time can reduce allostatic load by stimulating the pleasure and reward centers in the brain by producing chemicals such as dopamine andserotonin (Bodnar \& Klein, 2006). Alternatively, when employees respond to chronic load reactions by reducing time spent on exertive pursuits (i.e., mastery experiences and exercise) there is a commensurate loss of beneficial neurotransmitters that tend to counteract allostatic load (Koopmans, et al., 2005; Morgan, 1985). This is in line with Collary 1 of COR Theory, which further argues that individuals in a state of resource- depletion are at a higher risk for continued resource loss, known as a "loss spiral." The more extensive research depletion becomes, the more difficult it can be to replenish those resources. An employee experiencing high levels of resource depletion will need more extensive resource replenishment compared to an employee experiencing moderate resource depletion. Interestingly, while these results indicated that mastery experiences and exercise weaken the relationship between WHV and emotional exhaustion, these nonwork experiences did not weaken the relationships between WHV and other strain outcomes (e.g., impaired sleep and physical symptoms).

While I found some support that nonwork experiences moderated the relationship between WHV and strain outcomes for COs, the overall lack of support for the expected relationships provides important insight into nonwork experiences of COs. For example, this study found that psychological detachment did not moderate the relationship between 
WHV and any strain outcomes. This is surprising given that past research has documented psychological detachment as an especially powerful recovery experience, as well as a moderator in the relationship between job demands and strain (Sonnentag \& Fritz, 2015). There are several possible explanations as to why this research failed to support many of the proposed relationships.First, it is possible that the nonwork experiences included in this study (e.g., psychological detachment, relaxation) did not weaken the relationship between the job demand (i.e., WHV) and strain as they do whitecollar employees due to the nature of the work. Job characteristics are known to be important antecedents for employee wellbeing and recovery practices (Bennet et al., 2018). According to the "match hypothesis," nonwork experiences that employees engage in should match the job demands they experience at work in order to maximize the "undoing" of the job demands (de Jonge et al., 2012). In line with CATS, WHV recruits the use of physical (e.g. cardiovascular, neuroendocrine) and psychological resources (e.g. fear, worry). Whereas passive experiences (e.g., psychological detachment, relaxation) may allow for the restoration of musculoskeletal systems, some research has demonstrated more active, immersive, or fulfilling nonwork experiences are more effective in reducing strain in employees whose job demands are characterized by high mental or emotional intensity (Winwood, et al., 2007). This suggests that in order for COs, to "switch out," of work mode, psychological detachment and relaxation may be less beneficial than to "switch in" to another mode through mastery experiences and exercise during nonwork time.

Alternatively, the lack of support for the majority of the hypothesized 
relationships may be due to insufficient power to detect interaction effects. It is likely that the two significant interaction effects found in this study were the largest effect sizes, while smaller effect sizes were undetectable within this sample. Scholars have long recognized the difficulty in detecting interaction effects, particularly in field studies with continuous variables (Shieh, 2009). Previous research that has examined nonworkexperiences as moderators has found effect sizes similar to the current research $\left(R^{2}<.05\right.$; Moreno-Jiminez et al., 2009; Sonnentag et al., 2010). According to a post-hoc power analysis in $\mathrm{G}^{*}$ Power, I would need a sample size of 208 participants to detect a small effect size. Therefore, this sample was too small and underpowered to detect the hypothesized interactions. A sensitivity analysis demonstrated that in order to safely reject the null hypothesis, the critical F value in this study is 3.05. The two significant moderation effects were the only two results to surpass this threshold.

\section{Limitations and Future Directions}

The results of this study should be interpreted bearing in mind the strengths and limitations of the research design. The data analyzed in the current research were selfreport and cross-sectional. This poses several challenges for drawing causal conclusions from the study findings. First, because only measures of self-report were obtained, this study suffers from common method variance (Podsakoff et al., 2012). This means that the correlations between variables included in this study might be artificially inflated. Future research should explore different avenues for obtaining data that do not rely on selfreport. For example, objective measures of sleep and exertion during exercise could be obtained using wearable technologies such as actigraphy watches and heart rate monitors. 
Health impairment could also be measured more objectively, by obtaining number of sick days or doctor's visits. Further, future research should obtain data from alternative sources such as other household members in order to clarify the work-home interface for COs. For example, spouses of COs could report the amount of time spent engaged innonwork experiences, as well as the hassles COs face in the nonwork domain that may further contribute to strain (Demerouti et al., 2009).

Second, while cross-sectional studies can demonstrate how constructs are related to one another at one point in time, this research design is insufficient in order to determine how processes such as strain and recovery from work strain unfold over time. Thus, I am unable to draw any causal conclusions from this study. However, the research questions explored in this study are grounded in three widely supported theories (i.e., CATS, COR, and the E-RM), and warrant further investigation. For example, in line with COR's resource-investment principle, this study found that mastery experiences and exercise weaken the relationship between WHV and strain, which suggests that the moderation models might be theoretically accurate.

In the current study, post-hoc analyses demonstrated that emotional exhaustion is a significant predictor of WHV. In line with COR's loss spiral corollary, this suggests that as employees' wellbeing becomes impaired due to resource depletion, they appraise work conditions more negatively over time. While this research provides an initial snapshot of the proposed relationships, future research should examine this process utilizing longitudinal designs that occur over the long term (i.e., greater than one year). For example, researchers should conduct a longitudinal study examining newly hired 
COs in order to obtain baseline measures of strain. Over the course of months and years, this research could inform the temporal course of the relationship between WHV and strain outcomes.Finally, I argue that the lack of support for my proposed hypotheses may suggest that, until further research is conducted, nonwork experiences are not the most promising avenue for weakening the relationship between WHV and strain. Future researchers should investigate alternative moderators in the relationship between WHV and strain for COs. Job resources may weaken the relationship between WHV and strain by minimizing the effect of WHV on strain or providing a more effective means to cope with it. The Job Demands-Resources (JD-R) model suggests that resources may weaken the effect of job demands on strain outcomes (Bakker \& Demerouti, 2017). Within the JD-R model, resources can assist employees at organizational level (e.g., job security, promotion potential), job-design level (e.g., performance feedback, opportunities for development), task level (autonomy, task significance, skill variety), social or interpersonal level (e.g., supervisor support, spousal support), and the personal level (e.g., resilience, optimism, core self-evaluations). These resources are thought to mitigate the effect of job demands on strain by enhancing individual's ability to successfully meet job demands, aiding in coping, and reducing the physiological and psychological costs of job demands.

Certain resources (e.g., social support, autonomy) are thought to specifically aid in coping with stressful experiences. For example, Billings and colleagues (2000) found that, in a sample of caregivers to AIDS patients, those who practiced social support coping experienced more positive emotional states and fewer physical symptoms than 
GUARDING AGAINST STRAIN

caregivers who did not. Xanthopoulou and colleagues (2006) found that, in a sample of

home care workers, autonomy weakened the relationship between patient harassment and exhaustion. These resources may help COs cope with WHV such that strain outcomessuch as emotional exhaustion manifest less acutely, or not at all. Future research should therefore investigate whether job resources (e.g., social support, autonomy) the relationship between WHV and strain for COs.

\section{Practical Implications}

This research found initial evidence for the individual moderating effects of mastery experiences and exercise on the relationship between WHV and emotional exhaustion in COs. Therefore, COs should look for opportunities to engage in these nonwork experiences to foster personal resources which weaken the relationship between WHV and emotional exhaustion. Organizations may utilize this research by encouraging employees to generate personal resources by engaging in nonwork experiences that are rewarding to them. For example, an on-sight fitness center may encourage employees to exercise before or after work. In order to facilitate mastery experiences, organizations could subsidize skill-building classes. Further, supervisors should role model these behaviors to demonstrate to their employees a personal commitment to maintain their own wellbeing. Supervisors can also frequently encourage participation in these activities, as well as check in with individual employees regarding progress in their exercise or new skill.

COs themselves can facilitate their own resource-replenishment by prioritizing mastery experiences and exercise during their nonwork time. Individuals should schedule 
GUARDING AGAINST STRAIN

time for these experiences to increase participation after work or during the weekend, when amotivation may occur. Individuals may also enlist the participation a friend or partner to encourage maintenance, or even friendly competition in these endeavors. For example, Park \& Fritz (2015) found that spousal support for recovery can facilitate engagement in resource-generating activities during nonwork time, which was associated with higher life satisfaction in dual-earner couples. 


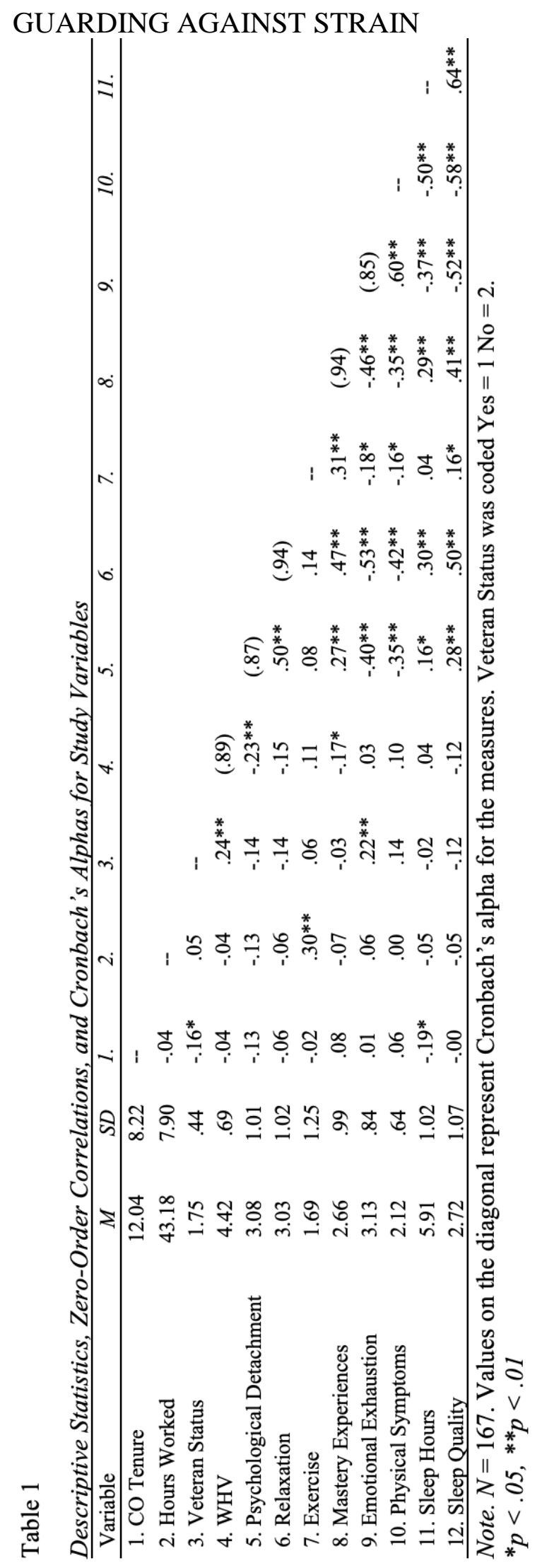




\section{GUARDING AGAINST STRAIN}

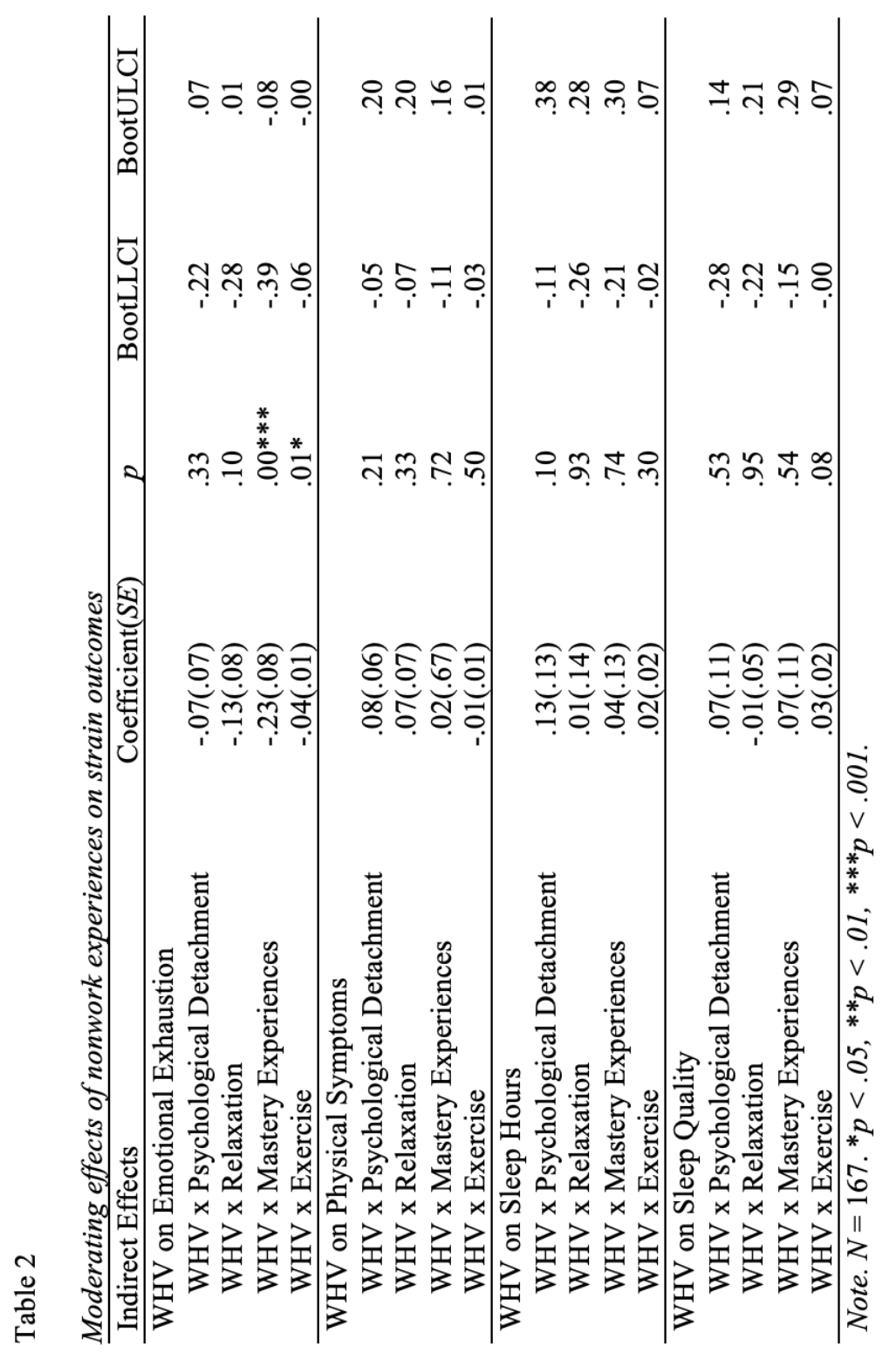




\section{GUARDING AGAINST STRAIN}

Table 3

Direct effects of WHV and nonwork experiences on strain outcomes

\begin{tabular}{lrc}
\hline Direct Effects & $\beta(S E)$ & $p$ \\
\hline WHV & $.28(.07)$ & $.00^{* * *}$ \\
Emotional Exhaustion & $.17(.07)$ & $.01^{*}$ \\
Physical Symptoms & $-.02(.14)$ & .89 \\
Sleep Hours & $-.00(.11)$ & .99 \\
Sleep Quantity & & \\
\hline Psychological Detachment & $-.18(.06)$ & $.00^{* * *}$ \\
Emotional Exhaustion & $-.11(.05)$ & $.03^{*}$ \\
Physical Symptoms & $.04(.11)$ & .74 \\
Sleep Hours & $.09(.09)$ & .28 \\
Sleep Quantity & & \\
\hline Relaxation & $-.17(.06)$ & $.01^{* *}$ \\
Emotional Exhaustion & $-.15(.06)$ & $.01^{* * *}$ \\
Physical Symptoms & $.25(.11)$ & $.00^{* * *}$ \\
Sleep Hours & $.37(.09)$ & $.01^{* * *}$ \\
Sleep Quantity & & \\
\hline Mastery Experiences & $-.10(.06)$ & .08 \\
Emotional Exhaustion & $-.12(.05)$ & $.00^{* * *}$ \\
Physical Symptoms & $.27(.11)$ & $.02^{*}$ \\
Sleep Hours & $.22(.09)$ & $.01^{* * *}$ \\
Sleep Quantity & & \\
\hline Exercise & $-.02(.01)$ & $.04^{*}$ \\
Emotional Exhaustion & $-.02(.01)$ & .06 \\
Physical Symptoms & $.01(.02)$ & .68 \\
Sleep Hours & $.03(.01)$ & .05 \\
Sleep Quantity & &
\end{tabular}

Note. $N=167 .{ }^{*} p<.05,{ }^{* *} p<.01,{ }^{* * *} p<.001$. 


\section{GUARDING AGAINST STRAIN}

Figure 1

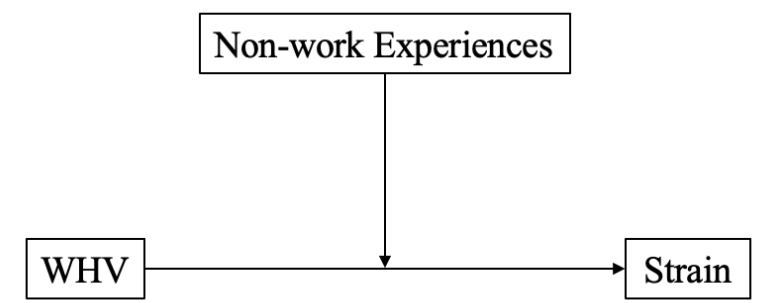

\section{Conceptual model}

Figure 2

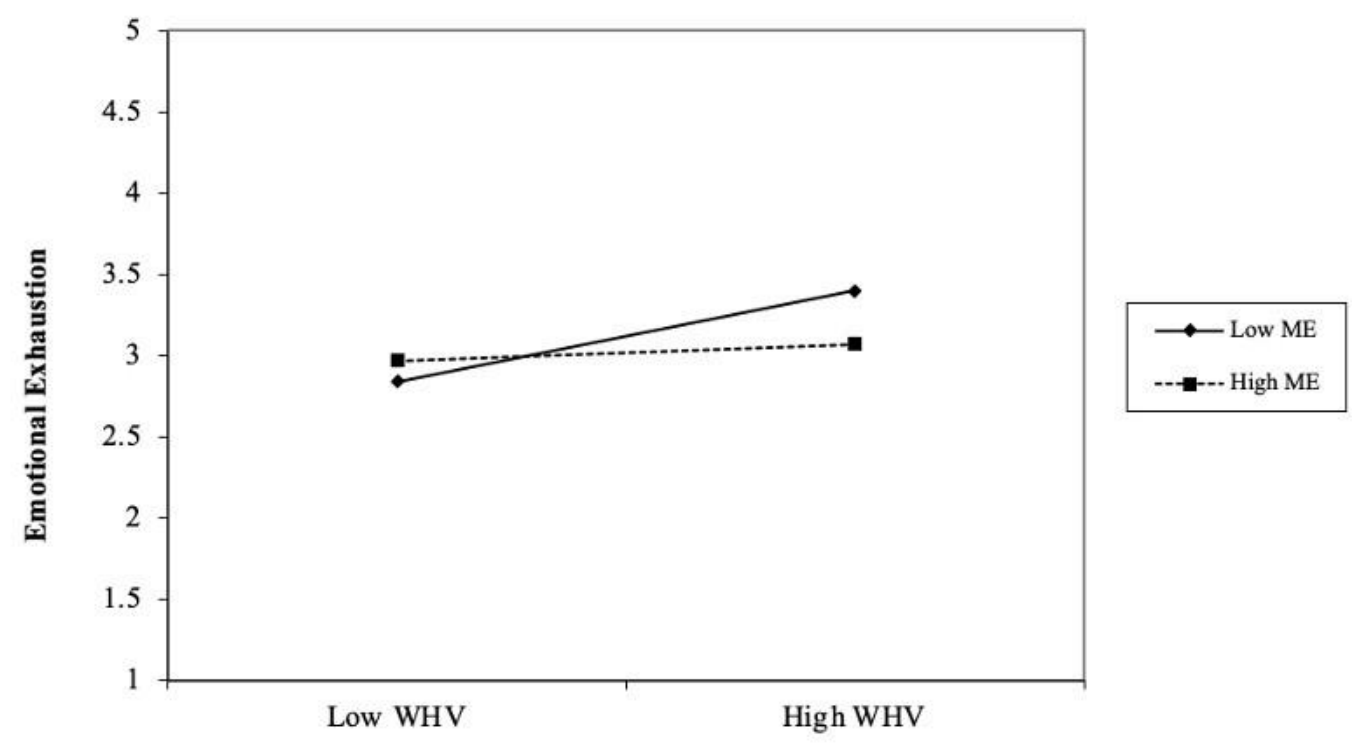

The moderating effect of mastery experiences on the relationship between WHV and emotional exhaustion Note. ME stands for mastery experiences. 


\section{GUARDING AGAINST STRAIN}

Figure 3

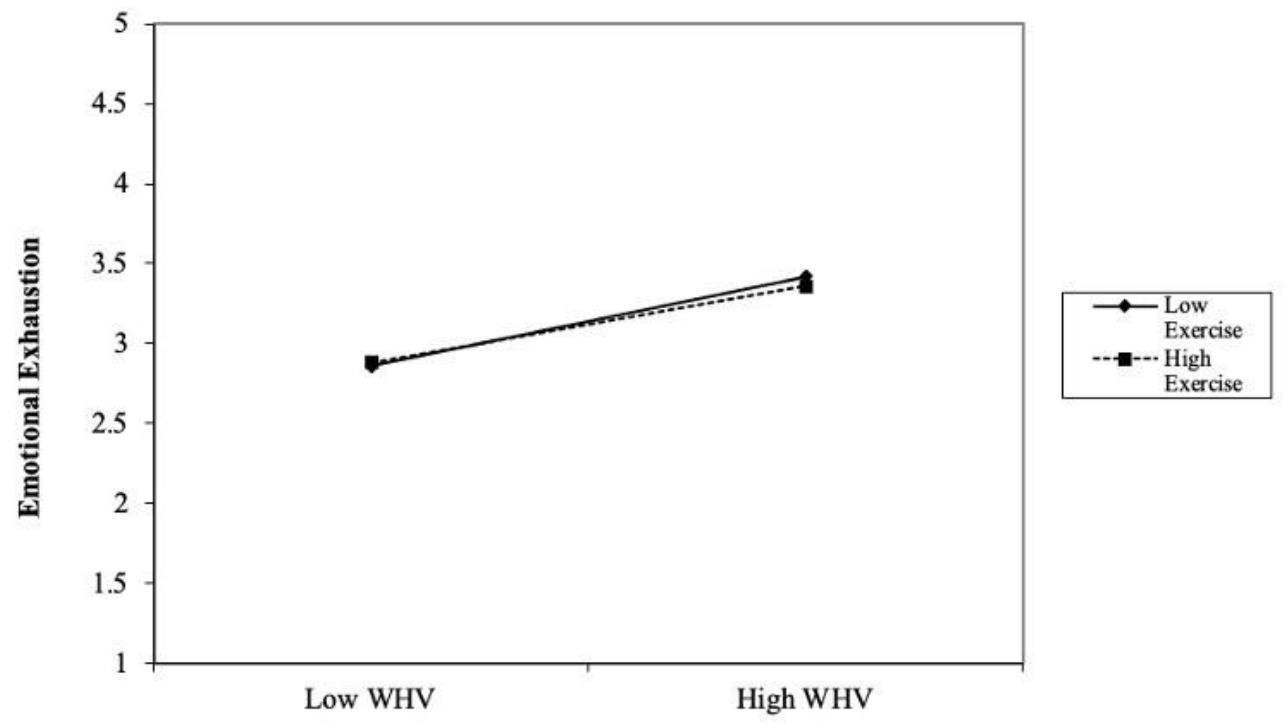

The moderating effect of exercise on the relationship between $W H V$ and emotional exhaustion 


\section{References}

Barber, L. K., Taylor, S. G., Burton, J. P., \& Bailey, S. F. (2017). A self-regulatory perspective of work-to-home undermining spillover/crossover: Examining the roles of sleep and exercise. Journal of Applied Psychology, 102(5), 753. https://doi.org/10.1037/ap10000196

Bakker, A. B., \& Demerouti, E. (2017). Job demands-resources theory: taking stock and looking forward. Journal of occupational health psychology, 22(3), 273. https://doi.org/10.1037/-ocp0000056

Bakker, A. B., Demerouti, E., Oerlemans, W., \& Sonnentag, S. (2013). Workaholism and daily recovery: A day reconstruction study of leisure activities. Journal of Organizational Behavior, 34(1), 87-107. https://doi.org/10.1002/job.1796

Bandura, A. (2001). Social cognitive theory: An agentic perspective. Annual Review of Psychology, 52, 1-26. https://doi.org/10.1146/annurev.psych.52.1.1

Barnes, C. M., Wagner, D. T., \& Ghumman, S. (2012). Borrowing from sleep to pay work and family: Expanding time-based conflict to the broader nonwork domain. Personnel Psychology, 65, 789-819. https://doi.org/10.1111/peps.12002

Basner, M., Rubinstein, J., Fomberstein, K. M., Coble, M. C., Ecker, A., Avinash, D., \& Dinges, D. F. (2008). Effects of night work, sleep loss and time on task on simulated threat detection performance. Sleep, 31, 1251-1259. https://doi.org/10.5665/sleep/31.9.1251 
Bennett, A. A., Bakker, A. B., \& Field, J. G. (2018). Recovery from work-related effort: A meta-analysis. Journal of Organizational Behavior, 39(3), 262-275. https://doi.org/10.1002-/job.2217

Billings, D. W., Folkman, S., Acree, M., \& Moskowitz, J. T. (2000). Coping and physical health during caregiving: The roles of positive and negative affect. Journal of Personality and Social Psychology, 79(1), 131. https://doi.org/10.1037/00223514.79.1.131

Bodnar, R. J., \& Klein, G. E. (2006). Endogenous opiates and behavior: 2005. Peptides, 27(12), 3391-3478. https://doi.org/10.1016/j.peptides.2006.07.011

Brosschot, J. F., Pieper, S., \& Thayer, J. F. (2005). Expanding stress theory: Prolonged activation and perseverative cognition. Psychoneuroendocrinology, 30, $1043-$ 1049. https://doi.-org/10.1016/j.psyneuen.2005.04.008

Bültmann, U., Kant, I., Kasl, S. V., Schröer, K. A., Swaen, G. M., \& van den Brandt, P. A. (2002). Lifestyle factors as risk factors for fatigue and psychological distress in the working population: prospective results from the Maastricht Cohort Study. Journal of Occupational and Environmental Medicine, 44(2), 116-124. https://doi.org/10.109-7/00043764-200202000-00006

Bureau of Labor Statistics. (2012). Nonfatal occupational injuries and illnesses requiring days away from work, 2010. https://www.bls.gov/news.release/archives/osh2_11082012.pdf

Buysse, D. J., Reynolds III, C. F., Monk, T. H., Berman, S. R., \& Kupfer, D. J. (1989). The Pittsburgh Sleep Quality Index: a new instrument for psychiatric practice and 
research. Psychiatry research, 28(2), 193-213. https://doi.org/10.1016/0165-

1781(89)90047-4

Cox, R. C. (2002). Exercise psychology. In: R. C. Cox (Ed.), Sports psychology, concepts and applications (5th ed, pp. 366-389). Boston: McGraw Hill.

Craig, A., \& Cooper, R. E. (1992). Symptoms of acute and chronic fatigue. In A. P. Smith, \& D. M. Jones (Eds.), Handbook of Human Performance (Vol. 3, pp. 289339). London: Academic Press. https://doi.org/10.1016/b978-0-12-650353$1.50017-4$

Day, J. C., Brauer, J. R., \& Butler, H. D. (2015). Coercion and social support behind bars: Testing an integrated theory of misconduct and resistance in US prisons. Criminal Justice and Behavior, 42(2), 133-155. https://doi.org/10.1177/0093854814546352

de Jonge, J., Spoor, E., Sonnentag, S., Dormann, C., \& van den Tooren, M. (2012). “Take a break?!" Off-job recovery, job demands, and job resources as predictors of health, active learning, and creativity. European Journal of Work and Organizational Psychology, 21, 321-348. https://doi.org/10.1080/1359432X.2011.576009

De Lange, A.H., Taris, T.W., Kompier, M.A.J., Houtman, I.L.D., \& Bongers, P.M. (2004). The relationships between work characteristics and mental health: Examining normal, reversed and reciprocal relationships in a 4-wave study. Work \& Stress, 18, 149-166. https://doi.org/10.1080/02678370412331270860 
Demerouti, E., \& Bakker, A. B. (2008). The Oldenburg Burnout Inventory: A good alternative to measure burnout and engagement. Handbook of stress and burnout in health care, 65-78. Retrieved from http://www.psicopolis.com/burnout/bumesur.pdf

Demerouti, E., Bakker, A.B., Geurts, S.A.E. and Taris, T.W. (2009), "Daily recovery from work-related effort during non-work time", Sonnentag, S., Perrewé, P.L. and Ganster, D.C. (Ed.) Current Perspectives on Job-Stress Recovery (Research in Occupational Stress and Well Being, Vol. 7), Emerald Group Publishing Limited, Bingley, pp. 85-123. https://doi.org/10.1108/S14793555(2009)0000007006

Demerouti, E., Bakker, A. B., Nachreiner, F., \& Schaufeli, W. B. (2001). The job demands-resources model of burnout. Journal of Applied Psychology, 86, 499512. https://doi.org/10.1037/0021-9010.86.3.499

Demerouti, E., Bakker, A. B., Vardakou, I., \& Kantas, A. (2003). The convergent validity of two burnout instruments: A multitrait-multimethod analysis. European Journal of Psychological Assessment, 19, 12- 23. https://doi.org/10.1027//10155759.19 .1 .12

Denhof, M. D., Spinaris, C. G., \& Morton, G. R. (2014). Occupational stressors in corrections organizations: Types, effects and solutions. Washington, DC: National Institute of Corrections. Retrieved from https://info.nicic.gov/nicrp/system/files/028299.

Elliot, D. L., Goldberg, L., Kuehl, K. S., Moe, E. L., Breger, R. K. R., \& Pickering, M. A. (2007). The PHLAME (promoting healthy lifestyles: Alternative models' effects) 
GUARDING AGAINST STRAIN

firefighter study: Outcomes of two models of behavior change. Journal of Occupational and Environmental Medicine, 49, 204-213. https://doi.org/10.1097/JOM.0b013e3180-329a8d

Feng, C., Wang, H., Lu, N., Chen, T., He, H., Lu, Y., \& Tu, X. M. (2014). Logtransformation and its implications for data analysis. Shanghai archives of psychiatry, 26(2), 105-109. https://doi.org/10.3969/j.issn.1002-0829.2014.02.009

Frayne, C. A., \& Geringer, J. M. (2000). Self-management training for improving job performance: A field experiment involving salespeople. Journal of Applied Psychology, 85, 361-372. https://doi.org/10.1037/0021-9010.85.3.361

Fritz, C., Hammer, L. B., Guros, F., Shepherd, B. R., \& Meier, D. (2018). On Guard: The Costs of Work-Related Hypervigilance in the Correctional Setting. Occupational Health Science, 2(1), 67-82. https://doi.org/10.1007/s41542-018-0010-z

Fredrickson, B. L. (2001). The role of positive emotions in positive psychology: The broaden- and-build theory of positive emotions. American Psychologist, 56, 218 226. https://doi.-org/10.1037/0003-066X.56.3.218

Freudenberger, H. J. (1974). Staff burn-out. Journal of Social Issues, 30(1), 159-165. https://d-oi.org/10.1111/j.1540-4560.1974.tb00706.x

Geurts, S. A., \& Sonnentag, S. (2006). Recovery as an explanatory mechanism in the relation between acute stress reactions and chronic health impairment. Scandinavian journal of work, environment \& health, 482492. https://doi.org/10.5271/sjweh.1053

Grossman, A., Bouloux, P., Price, P., Drury, P. L., Lam, K. S., Turner, T., Thomas, J., Besser, 
GUARDING AGAINST STRAIN

G. M., \& Sutton, J. (1984). The role of opioid peptides in the hormonal responses

to

acute exercise in man. Clinical Science, 67, 483-491.

https://doi.org/10.1042/cs0670483

Halbesleben, J. R., Wheeler, A. R., \& Paustian-Underdahl, S. C. 2013. The impact of furloughs on emotional exhaustion, self-rated performance, and recovery experiences. Journal of Applied Psychology, 98: 492-503. https://doi.org/10.1037/a0032242

Hobfoll, S. E., Halbesleben, J., Neveu, J. P., \& Westman, M. (2018). Conservation of resources in the organizational context: The reality of resources and their consequences. Annual Review of Organizational Psychology and Organizational Behavior, 5, 103-128. https://doi.org/10.1146/annurev-orgpsych-032117-104640

Hoobler, J. M., \& Brass, D. J. (2006). Abusive supervision and family undermining as displaced aggression. Journal of Applied Psychology, 91(5), 1125. https://doi.org/10.1037/0021-9010.91.5.1125

Juster, R. P., Sindi, S., Marin, M. F., Perna, A., Hashemi, A., Pruessner, J. C., \& Lupien, S. J. (2011). A clinical allostatic load index is associated with burnout symptoms and hypocortisolemic profiles in healthy workers. Psychoneuroendocrinology, 36, 797-805. https://doi.org/10.1016/j.psyneuen.2010.11.001

Stephan, J. J., \& Karberg, J. C. (2003). Census of state and federal correctional facilities, 2000. Washington, DC: US Department of Justice, Office of Justice Programs, Bureau of Justice Statistics. Retrieved from https://www.prisonpolicy.org/scans/bjs/csfcf05.pdf 
Kimble, M. O., Fleming, K., \& Bennion, K. A. (2013). Contributors to hypervigilance in a military and civilian sample. Journal of Interpersonal Violence, 28, 1672-1692. https://doi.org/10.1177/0886260512468319

Kinnunen, U., \& Feldt, T. (2013). Job characteristics, recovery experiences and occupational well-being: Testing cross-lagged relationships across 1 year. Stress and Health, 29(5), 369-382. https://doi.org/10.1002/smi.2483

Kinnunen, U., Feldt, T., Siltaloppi, M., \& Sonnentag, S. 2011. Job demands-resources model in the context of recov- ery: Testing recovery experiences as mediators. European Journal of Work and Organizational Psychology, 20: 805-832. https://doi.org/10.1080/13594-32X.2010.524411

Kinnunen, U., Mauno, S., \& Siltaloppi, M. (2010). Job insecurity, recovery and wellbeing at work: Recovery experiences as moderators. Economic and industrial democracy, 31(2), 179-194. https://doi.org/10.1177/0143831X09358366

Konda, S., Reichard, A. A., \& Tiesman, H. M. (2012). Occupational injuries among US correctional officers, 1999-2008. Journal of safety research, 43(3), 181-186. https://doi.org/10.1016/j.jsr.2012.06.002

Koopmans, S. J., Ruis, M., Dekker, R., van Diepen, H., Korte, M., \& Mroz, Z. (2005). Surplus dietary tryptophan reduces plasma cortisol and noradrenaline concentrations and enhances recovery after social stress in pigs. Physiology \& behavior, 85(4), 469-478. https://doi.org/10.1016/j.physbeh.2005.05.010

Kristal-Boneh, E., Froom, P., Harari, G., \& Ribak, J. (1996). Fatigue among Israeli industrial employees. Journal of occupational and environmental 
medicine, 38(11), 1145-1150. https://doi.org/10.1097/00043764-199611000-

00015

Lambert, E. G., Hogan, N. L., \& Griffin, M. L. (2007). The impact of distributive and procedural justice on correctional staff job stress, job satisfaction, and organizational commitment. Journal of Criminal Justice, 35(6), 644-656. https://doi.org/10.1016/j.jcrimju-s.2007.09.001

LePine, J. A., Podsakoff, N. P., \& LePine, M. A. (2005). A meta-analytic test of the challenge stressor-hindrance stressor framework: An explanation for inconsistent relationships among stressors and performance. Academy of management journal, 48(5), 764-775. https://doi.org/10.5465/amj.2005.18803921

Lim, J., \& Dinges, D. F. (2010). A meta-analysis of the impact of short-term sleep deprivation on cognitive variables. Psychological Bulletin, 136, 375-389. https://doi.org/10.1037/a0-018883

McEwen, B. S. (1998). Stress, adaptation, and disease: Allostasis and allostatic load. Annals of the New York Academy of Sciences, 840, 33-44. https://doi.org/10.1111/j.1749-6632.1998.tb09546.x

McEwen, B.S., Stellar, E., 1993. Stress and the individual. Mechanisms leading to disease. Arch. Intern. Med. 153, 2093 - 2101. https:// doi:10.1001/archinte.1993.00410180039004

Meijman, T. F., \& Mulder, G. (1998). Psychological aspects of workload. In P. J. D. Drenth, \& H. Thierry (Eds.), Handbook of work and organizational psychology, vol. 2: Work psychology (pp. 5-33). Hove, UK: Psychology Press. (eBook ISBN: 9780203765425) 
Meurs, J. A., \& Perrewé, P. L. (2011). Cognitive activation theory of stress: An integrative theoretical approach to work stress. Journal of Management, 37, 1043-1068. https://doi.org/10.1177/0149206310387303

Moreno-Jiménez, B., Rodrígez-Munoz, A., Sanz-Vergel, A. I., \& Garrosa, E. (2012). Elucidating the role of recovery experiences in the job demands-resources model. The Spanish Journal of Psychology, 15, 659-669. https://doi.org/10.5209/rev_SJOP.2012-.v15.n2.38877

Morgan, W. P. (1985). Affective beneficence of vigorous physical activity. Medicine \& Science in Sports \& Exercise. https://doi.org/10.1249/00005768-19850200000015

Neely, P., \& Cleveland, C. S. (2012). The impact of job-related stressors on incidents of excessive force by police officers. American Journal of Health Sciences (AJHS), 3(1), 63-74. https://doi.org/10.19030/ajhs.v3i1.6755

Neff, J., \& Santo, A. (2020, February 2). Mississippi Prisons: No One’s Safe, Not Even the Guards [Editorial]. The Marshall Project. Retrieved from https://www.themars-hallproject.org/2020/02/20/mississippi-prisons-no-one-ssafe-not-even-the-guards

Parker, J. R. (2011). Florida mortality study: Florida law enforcement and correctional officers compared to Florida general population. Retrieved from: http://www.floridastatefop.o-rg/pdf_files/floridamortalitystudy.pdf

Podsakoff, P. M., MacKenzie, S. B., Lee, J. Y., \& Podsakoff, N. P. (2003). Common method 
GUARDING AGAINST STRAIN

biases in behavioral research: A critical review of the literature and recommended remedies. Journal of Applied Psychology, 88, 879-903.

https://doi.org/10.1037/0021-9010.88.5.879

Raglin, J. S., \& Morgan, W. P. (1985). Influence of vigorous exercise on mood state.

Behavior Therapy, 8, 179-183. https://doi.org/10.1249/00005768-19871000000006

Reid, L. E., Upchurch, J. L., Palmateer, J. L., Turley, S., \& Jeffreys, R. (2017). NCDPS Security Operational Assessment (pp. 17-21) (United States, National Institute of Corrections, Prisons). Raleigh, NC: National Institute of Corrections. Retrieved from https://www.ncdps.gov/documents/security-operational-assessment

Regehr, C., Carey, M., Wagner, S., Alden, L. E., Buys, N., Corneil, W., ... \& White, N. (2019). Prevalence of PTSD, depression and anxiety disorders in correctional officers: A systematic review. Corrections, 1-13. https://doi.org/10.1080/23774657.2019.1641765

Rook, J. W., \& Zijlstra, F. R. (2006). The contribution of various types of activities to recovery. European journal of work and organizational psychology, 15(2), 218240. https://doi.org/10.1080/13594320500513962

Sawhney, G., Jennings, K. S., Britt, T. W., \& Sliter, M. T. (2018). Occupational stress and mental health symptoms: Examining the moderating effect of work recovery strategies in firefighters. Journal of occupational health psychology, 23(3), 443. https://doi.org/10.1037/ocp0000091 
Schaufeli, W. B., \& Peeters, M. C. (2000). Job stress and burnout among correctional officers: A literature review. International Journal of Stress Management, 7, 1948. https://doi.org/-10.1023 /A:1009514731657

Seeman, T. E., Singer, B. H., Rowe, J. W., Horwitz, R. I., \& McEwen, B. S. (1997). Price of adaptationent role of hyperarousal in the natural course of posttraumatic psychological distress. Archives of Internal Medicine, 157, 2259-2268.

Shieh, G. (2009). Detecting interaction effects in moderated multiple regression with continuous variables power and sample size considerations. Organizational Research Methods, 12(3), 510-528. https://doi.org/10.1177/1094428108320370

Shimazu, A., Schaufeli, W. B., Kubota, K., \& Kawakami, N. (2012). Do workaholism and work engagement predict employee well-being and performance in opposite directions?. Industrial health, 50(4), 316-

321. https://doi.org/10.2486/indhealth.ms1355

Siltaloppi, M., Kinnunen, U., \& Feldt, T. (2009). Recovery experiences as moderators between psychosocial work characteristics and occupational well-being. Work \& Stress, 23(4), 330-348. https://doi.org/10.1080/02678370903415572

Sonnentag, S. (2001). Work, recovery activities, and individual well-being: A diary study.

Journal of Occupational Health Psychology, 6, 196210. https://doi.org/10.1037/1076-8998.6.3.196

Sonnentag, S., \& Binnewies, C. (2013). Daily affect spillover from work to home: Detachment from work and sleep as moderators. Journal of Vocational Behavior, 83(2), 198-208.Sonnentag, S., \& Fritz, C. (2007). The recovery 
GUARDING AGAINST STRAIN

experience questionnaire: Development and validation of a measure for assessing recuperation and unwinding from work. Journal of Occupational Health

Psychology, 12: 204-221. https://doi.org/10.-1016/j.jvb.2013.03.008

Sonnentag, S., \& Fritz, C. 2015. Recovery from job stress: The stressor-detachment model as an integrative framework. Journal of Organizational Behavior, 36: 72103. https://doi.org_-_10.1002/job.1924

Sonnentag, S., \& Geurts, S. A. E. (2006). Methodological issues in recovery research. In P. L. Perrewé, \& D. C. Ganster (Eds.), Research in occupational stress and wellbeing (Vol. 7) (pp. 1-36) Emerald Group Publishing. https://doi.org/10.1108/S14793555(2009)00-00007004

Sonnentag, S., \& Jeldon, S. (2005). The recovery paradox: Why we don't exercise after stressful days. Poster presented at the conference of the Society for Industrial and Organizational Psychology, Los Angeles. https://doi.org/10.1037/e518612013265

Sonnentag, S., \& Natter, E. (2004). Flight attendants' daily recovery from work: Is there no place like home? International Journal of Stress Management, 11, 366391. https://doi.org/-10.1037/1072-5245.11.4.366

Sonnentag, S., Venz, L., \& Casper, A. (2017). Advances in recovery research: What have we learned? What should be done next?. Journal of Occupational Health Psychology, 22: 365-380. https://doi.org/10.1037/ocp0000079

Spector, P. E., \& Jex, S. M. (1998). Development of four self-report measures of job stressors and strain: Interpersonal Conflict at Work Scale, Organizational Constraints Scale, Quantitative Workload Inventory, and Physical Symptoms 
GUARDING AGAINST STRAIN

Inventory. Journal of Occupational Health Psychology, 3, 356-367. https://doi. org/10.1037/1076-8998.3.4.356

Stack, S. J., \& Tsoudis, O. (1997). Suicide risk among correctional officers: A logistic regression analysis. Archives of Suicide Research, 3, 183-186. https://doi.org/10.1080/13811119708258270

Steed, L. B., Swider, B. W., Keem, S., \& Liu, J. T. (2021). Leaving work at work: a meta-analysis on employee recovery from work. Journal of Management, 47(4), 867-897. https://doi.org/10.1177/0149206319864153

Toker, S., \& Biron, M. (2012). Job burnout and depression: unraveling their temporal relationship and considering the role of physical activity. Journal of Applied Psychology, 97(3), 699. https://doi.org/10.1037/a0026914

Tucker, J. S., Sinclair, R. R., Mohr, C. D., Adler, A. B., Thomas, J. L., \& Salvi, A. D. (2008). A temporal investigation of the direct, interactive, and reverse relations between demand and control and affective strain. Work \& Stress, 22(2), 81-95. https://doi.org/10.1080/02-678370802190383

Tuckey, M. R., Boyd, C. M., Winefield, H. R., Bohm, A., Winefield, A. H., Lindsay, A., \& Black, Q. (2017). Understanding stress in retail work: Considering different types of job demands and diverse applications of job resources. International Journal of Stress Management, 24(4), 368. https://doi.org/10.1037/str0000032 United States. Department of Justice. Office of Justice Programs (2020, March) Data Collected Under the First Step Act, 2019. (Research in brief) Retrieved from: https://www.bjs-.gov/index.cfm?ty=dcdetail\&iid=255 
Ursin, H., \& Eriksen, H. R. (2004). The cognitive activation theory of stress. Psychoneuroendocrinology, 29, 567-592. https://doi.org/10.1016/S0306-4530(03)00091X

Wagner, P., \& Sawyer, W. (2018, March 14). Mass Incarceration: The Whole Pie 2018. Retrieved from https://www.prisonpolicy.org/reports/pie2018.html

Winwood, P. C., Bakker, A. B., \& Winefield, A. H. (2007). An investigation of the role of non-work-time behavior in buffering the effects of work strain. Journal of Occupational and Environmental Medicine, 49(8), 862-871. https://doi.org/10.1097/JOM.0b013e3181-24a8dc

Xanthopoulou, D., Bakker, A. B., Demerouti, E., \& Schaufeli, W. B. (2007). The role of personal resources in the job demands-resources model. International journal of stress management, 14(2), 121-141. https://doi.org/10.1037/1072-5245.14.2.121 


\section{Appendix: Survey Items}

\section{Hypervigilance (Fritz et al., 2018)}

To what extent do you agree with the following statements? In the past month...

1. I had to be on guard to stay safe.

2. Bad things may have happened if I had not constantly been looking out for danger.

3. I may have put myself and the people around me in danger if I had not always been on guard.

4. I always kept an eye out for potential danger.

5. If I relaxed, I may have made myself more vulnerable to dangerous situations

Response Options: (1) Not at all to (5) Very much.

\section{Physical Symptoms (Spector \& Jex, 1997)}

Over the past month, how often have you experienced each of the following symptoms?

1. An upset stomach or nausea.

2. Trouble sleeping.

3. Headache.

4. Acid indigestion or heartburn.

5. Eye strain.

6. Diarrhea.

7. Stomach cramps (Not menstrual).

8. Constipation.

9. Ringing in the ears.

10. Loss of appetite.

11. Dizziness.

12. Tiredness or fatigue.

Response Options: (1) Not at all, (2) Once or twice, (3) Once or twice per week, (4) Most days, or (5) Everyday

Burnout (Demerouti et al., 2003)

To what extent do you agree with the following statements? In the past month...

\section{Exhaustion}

1. There were days that I felt already tired before I went to work.

2. After my work, I needed more time to relax than in the past to become fit again.

3. I could stand the pressure of my work very well. *

4. During my work, I often felt emotionally drained.

5. After my work, I usually felt still totally fit for my leisure activities. *

6. After my work, I usually felt worn out and weary.

7. When I worked, I usually felt vital. * 
8. I could manage the amount of work well. *

Response Options: (1) Not at all to (5) Very much.

Recovery Experience Questionnaire (Sonnentag \& Fritz, 2007)

To what extent do you agree with the following statements? OUTSIDE OF WORK, in the past month...

Detachment

1. I forgot about work.

2. I didn't think about work at all.

3. I distanced myself from work.

4. I got a break from the demands of work.

\section{Relaxation}

1. I kicked back and relaxed.

2. I did things that were relaxing.

3. I used the time to relax.

4. I took time for leisure.

Mastery

1. I learned new things.

2. I sought out mental challenges.

3. I did things that challenged me.

4. I did something to broaden my horizons.

Pittsburg Sleep Quality Index (Select questions; Buysse, et al., 1989)

1. During the past month, on average, how many hours of actual sleep did you get at night? (This may be different than the number of hours you spend in bed.)

Fill-in: HOURS OF SLEEP PER NIGHT (on average)

2. During the past month, how would you rate your sleep quality overall?

Response Options: (1) Very bad, (2) Fairly bad, (3) Neither good nor bad, (4) Fairly good, or (5) Very good

\section{Sleep Sufficiency}

1. How often during the past month did you get enough sleep to feel rested upon waking up?

Response Options: (1) Not during the past month, (2) Less than once per week, (3) Once or twice per week, (4) Three or more times a week, or (5) Everyday 


\section{Exercise (Select questions; Elliot, et al., 2007)}

Please answer the next 5 questions as they have applied to your over the past 1 month.

1. How many days per week did you exercise or take part in moderate physical activities that increased your breathing a bit for a total of at least 30 minutes during the day (such as basketball, jogging, swimming laps, tennis, fast bicycling, strength training, or similar activities)?

2. How many days per week did you exercise or take part in moderate physical activities that increased your breathing a bit for a total of at least 30 minutes during the day (such as brisk walking or bicycling)? Do not include activities from the question above.

3. How many days per week did you exercise to strengthen or tone your muscles, such as push-ups, sit-ups, or weight lifting?

4. In a typical week, how many days do you take part in any physical activity long enough to work up a sweat?

5. I exercise for 30 minutes almost every day.

(1) Strongly Disagree to (7) Strongly Agree

\section{Demographics}

Age

What is your age?

Fill-in: years

\section{Gender}

What is your gender?

Response Options (Circle one): (a) Male or (b) Female.

\section{Marital Status}

What is your marital status?

Response Options (Circle one): (a) Single, never married, (b) Dating someone, (c) Married, (d) Living with a partner, (e) Divorced, or (f) Widowed.

\section{Ethnicity}

What is your ethnicity?

Response Options (Circle all that apply): (a) White (non-Hispanic), (b) Hispanic/Latino, (c) African American, (d) Asian, (e) Native American, (f) Native Alaskan or Pacific Islander, or (g) Other (please specify:

\section{Education Level}

What is the highest level of education you have completed? 
GUARDING AGAINST STRAIN

Response Options (Circle one): (a) High school/GED, (b) Some college, (c) 2-year college degree (Associate's), (d) 4-year college degree (Bachelor's), (e) Advanced degree (Master's or other), or (f) Other (please specify:

\section{Number of Dependents in Household}

How many children do you have that are living with you at least half time?

Fill-in:

\section{Elder Care}

During the past month have you provided at least 3 hours of care per week to an adult relative inside or outside of your home? This could include help with shopping, medical care, or assistance in financial/budget planning?

Response Options (1) Yes (2) No

\section{Rank}

What is your current rank?

Response Options (Circle one): (a) Correction Officer (b) Corporal (c) Sergeant (d)

Lieutenant (e) captain

\section{OIC Status}

Are you currently a ...?

Response Options (Circle one): (a)OIC (b) AOIC (c) Neither

\section{Facility}

At which facility do you currently work?

Response Options: (a) TRCI, (b) EOCI

\section{Facility Security Level}

What is the security level of inmates you've worked with the most in the past month?

Response Options: (a) Minimum, (b) Medium, or (c) Maximum

\section{Which shift do you currently work?}

Which best describes the shift you work?

Response Options: (a) Day Shift, (b) Swing Shift, or (c) Night Shift.

\section{Tenure as a $\mathrm{CO}$}

How long have you been working as a correctional officer?

Fill-in: years

\section{Tenure in current facility}

How long have you been working at your current facility?

Fill-in: years

\section{Veteran Status}

Have you ever served on active duty in the U.S. Armed Forces? 
GUARDING AGAINST STRAIN

Response Options (Circle one): (a) Yes or (b) No.

\section{Hours worked per week}

On average in the past month, how many hours did you work per week?

Fill-in: hours

\section{Direct Supervisor}

Who is currently your direct supervisor that, of any of your supervisors, you spent the most time interacting with over the past month?

Fill-in:

\section{Other Supervisors}

Do you have other supervisors that you interacted with on a regular basis during your shifts in the last month? Please list them below.

Fill-in: 